\title{
Effects of Temperature on Gonadal Sex Determination in Barfin Flounder Verasper moseri
}

\author{
Rie Goto, ${ }^{* 1}$ Tatsunari Mori, ${ }^{* 2}$ Kenji Kawamata, ${ }^{* 2}$ Takahiro Matsubara, ${ }^{* 3}$ \\ Shinya Mizuno, ${ }^{* 1}$ Shinji Adachi, ${ }^{*}$ and Kohei Yamauchi ${ }^{* 1}$ \\ ${ }^{*}$ Department of Biology, Faculty of Fisheries, Hokkaido University, Hakodate 041-8611, Japan \\ ${ }^{*}$ Hokkaido Institute of Mariculture, Shikabe, Kayabe, Hokkaido 041-1400, Japan \\ ${ }^{*}$ Hokkaido National Fisheries Research Institute, Fisheries Agency of Japan, Katsurakoi, Kushiro, \\ Hokkaido 085-0802, Japan
}

(Received March 18, 1999)

\begin{abstract}
Temperature-dependent sex determination has been demonstrated in several species of fish. This study analyzes this phenomenon in barfin flounder Verasper moseri. The sex ratio was 1:1 when fish were maintained at $14^{\circ} \mathrm{C}$ from Day 34 to Day 95 . However, acclimation to $18^{\circ} \mathrm{C}$ for 62 days resulted in an all male population. The proportion of males from $10.1 \mathrm{~mm}$ up to $29.7 \mathrm{~mm}$ in total length was affected by high temperature treatments. Survival rates were not affected by these treatments. Morphological differentiation of the gonad into either ovary or testis became distinguishable at $35 \mathrm{~mm}$ in total length. This time corresponds to the end of the temperature-sensitive period. These results suggest that gonadal sex was determined by temperature prior to the onset of gonadal sex differentiation in this fish.
\end{abstract}

Key words: barfin flounder, sex determination, temperature

It has been documented that sex in fish is controlled genetically. However, many fish do not have a clear chromosomal sex determining system, ${ }^{1)}$ and therefore, genetic sex and phenotypic sex should be considered as separate entities. Studies over the past decade have shown that external factors, such as temperature and $\mathrm{pH}$, influence sexual determination in some fish. Thus, temperature-dependent sex determination has been demonstrated in Menidia menidia, ${ }^{2)}$ Oreochromis niloticus ${ }^{3)}$ and Odontesthes bonariensis ${ }^{4}$ ) while $\mathrm{pH}$-dependent sex determination has been demonstrated in Xiphophorus spp. ${ }^{5}$ and Apistogram$m a$ spp. ${ }^{6}$ The hirame flounder Paralichthys olivaceus ${ }^{7}$ in particular, has been well-studied in terms of genetic sex determination and manipulation of physiological sex by controlling temperature. It has been demonstrated in this species, in which the male is the heterogametic sex (XX female-XY male), that genetic females reverse their sex to male if the water temperature is manipulated. Not only high but also low temperatures produced male-biased sex ratios, while intermediate temperatures yielded a 1:1 sex ratio.

Thermolability of sex determination in another flatfish species, the barfin flounder Verasper moseri, a teleost that belongs to the Pleuronectidae family and inhabits cold seawater basins, has not been addressed. It is a commercially important species in Hokkaido and requires establishment of breeding techniques for aquaculture, like the hirame flounder. As in many other teleosts ${ }^{8-10)}$ gonadal sex in the barfin flounder can be manipulated by treatment with exogenous steroids during the period of gonadal sex differentiation. ") However, it became evident that the population frequently had a biased sex ratio under artificial breeding conditions. A supply of seedlings with stable sex ratio for stock enhancement has not yet been realized for this spe- cies. As in the hirame flounder, the biased sex ratio in barfin flounder could be caused by temperature influencing sex determination. To test this hypothesis, we evaluated sex ratios following manipulation of the temperature during the larval and juvenile stage. Manipulations were done periodically in order to identify temperature sensitive periods and to relate these periods to gonadal morphology.

\section{Materials and Methods}

\section{Animals}

Fertilized eggs of barfin flounder were acquired from a few captive-bred males and females held together in a $1 \mathrm{~m}^{3}$ tank at the Hokkaido Institute of Mariculture, Shikabe, Japan. After egg incubation and hatching at $8^{\circ} \mathrm{C}$, temperatures were gradually increased up to $14^{\circ} \mathrm{C}$ in 34 days. Animals were reared in flow-through seawater, larvae being fed Brachionus and Artemia nauplii, while juveniles were fed artificial diets.

\section{Experimental Design}

The experimental water temperatures were set at $14^{\circ} \mathrm{C}$ and $18^{\circ} \mathrm{C}$. On Day 34 after fertilization, six groups of $145-$ 175 fry from the same stock were placed in separate tanks and fed for different rearing periods at low temperature as follows (Fig. 1): in the first group, temperature was gradually increased up to $18^{\circ} \mathrm{C}$ by Day 62 (A). The second group was reared at $14^{\circ} \mathrm{C}$ from Day 34-Day 62, whereafter the temperature was shifted to $18^{\circ} \mathrm{C}$ over 3 days (B). Similarly, remaining groups were maintained at $14^{\circ} \mathrm{C}$ until Day 79 (C), Day 95 (D), Day 106 (E), and Day 120 (F), prior to increasing the temperature to $18^{\circ} \mathrm{C}$ as described for $\mathrm{B}$. At the end of all temperature manipulations, the groups were 


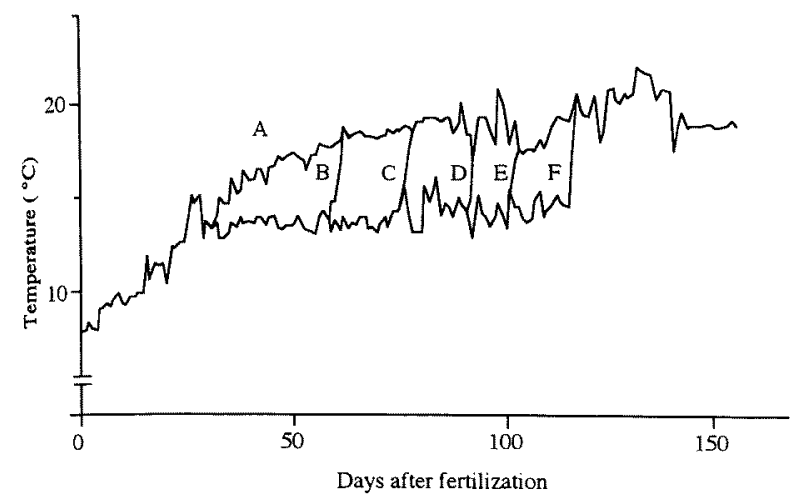

Fig. 1. Temperature regimes for experimental fish.

Eggs were fertilized, incubated and hatched at $8^{\circ} \mathrm{C}$, after which the temperature was increased gradually to $14^{\circ} \mathrm{C}$. Fry were subdivided between 6 groups on Day 34 and gradually acclimated to $18^{\circ} \mathrm{C}$ by 62 days (Group A), or rapidly transferred to $18^{\circ} \mathrm{C}$ over a $2-3$ day period, starting on Day 62 (Group B), 79 (Group C), 95 (Group D) 106 (Group E) or 120 (Group F). Thereafter fish were maintained at $18-20^{\circ} \mathrm{C}$ until the end of the experiment on Day 161

reared at $18-20^{\circ} \mathrm{C}$ until the time of sexing on Day 161 .

\section{Histological Observations}

Just before each experiment (Fig. 1), a sample of 5-20 fry was removed from the same batch held at $14^{\circ} \mathrm{C}$, body length and body weight were recorded, and gonads or gonadal regions excised and fixed in Bouin's fluid. Fixed tissues were processed for routine paraffin embedding, and transverse sections of the gonads cut serially at $4-5 \mu \mathrm{m}$ in thickness and stained with Delafield's hematoxylin and eosin.

\section{Analysis of Sex Ratios}

On day 161, all fish were measured and preserved in Bouin's solution for sexing. In barfin flounder, sexual dimorphism in gonads of immature fish is obvious from the shape of the gonads, as reported by Matsubara et al. ${ }^{12)}$ Preliminary sampling of fish for this study exhibited clear sexual dimorphism as low as approximately $80 \mathrm{~mm}$ in total length. Therefore sexing could be carried out by observation of the removed gonads with the naked eye at final sampling.

\section{Statistic Analysis}

The significance of the deviations in sex ratios and survival ratios from the theoretical 1:1 (female : male) ratio were analysed by $\chi^{2}$-test. The data of total length at 161 days were examined in each group by one-way ANOVA multiple comparisons. $P$-values $<0.05$ are regarded as significant.

\section{Results}

\section{Sex Ratio in Each Experimental Group}

The sex ratio inclined towards zero, i.e., the male sex greatly predominated when fish were reared at high temperature $\left(18^{\circ} \mathrm{C}\right)$ (Table. 1). Thus, the sex of fish in Group A, which were gradually acclimated to $18^{\circ} \mathrm{C}$ when $10 \mathrm{~mm}$ in TL, was exclusively male, whereas a group of fish shifted from $14^{\circ} \mathrm{C}$ to $18^{\circ} \mathrm{C}$ at a mean TL of $20 \mathrm{~mm}$ (B) yielded $83.5 \%$ males. The proportion of males decreased if temperature changes were delayed until fish had reached $30 \mathrm{~mm}$ (C; $61.5 \%)$ or $40 \mathrm{~mm}(\mathrm{D} ; 56.1 \%)$. Similarly, groups of fish shifted from $14^{\circ} \mathrm{C}$ to $18^{\circ} \mathrm{C}$ at a later stage, at TL of $50 \mathrm{~mm}$ (E) or $60 \mathrm{~mm}$ (F) produced 48.0 and $49.0 \%$ males, respectively. Sex ratios in Groups A, B and C were significantly different from the theoretical $1: 1$.

\section{Survival and Growth Rates}

Growth rates, but not survival rates, were positively affected by temperatures (Fig. 2). Accordingly, growth in the high temperature treatment (A) was greater than that in the other groups during the experiment. Interestingly, though, after the water temperature was increased from $14^{\circ} \mathrm{C}$ to $18^{\circ} \mathrm{C}$, fish showed a higher, compesatory growth rate than the $18^{\circ} \mathrm{C}$ treatment group. The statistically significant differences between groups at the time of the final sampling on Day 161 are represented in Fig. 2.

\section{Histological Observations}

In the present study, observations are presented from the starting point of sex differentiation when changes become noticeable morphologically. There was a correlation between gonadal morphology and total length (TL) in this fish, so that observations depended on TL rather than days after fertilization.

At $35-56 \mathrm{~mm}$ in TL, the dorsal and ventral edges of these gonads began to extend laterally and eventually fused to form the ovarian cavities along the lateral sides of

Table 1. Numbers of males and females of barfin flounder when maintained at different rearing temperatures

\begin{tabular}{|c|c|c|c|c|c|c|c|}
\hline Group & $\begin{array}{c}\left(14 \rightarrow 18^{\circ} \mathrm{C}\right) \\
\text { Mean TL }(\mathrm{mm})\end{array}$ & $\begin{array}{l}\text { Days after } \\
\text { fertilization }\end{array}$ & Total & Female & Male & $\%$ Female & $\%$ Survival \\
\hline A & 10.1 & $32 \#$ & 143 & 0 & 143 & $0^{*}$ & 98.6 \\
\hline B & 20.6 & 61 & 170 & 28 & 142 & $16.5^{*}$ & 97.1 \\
\hline $\mathrm{C}$ & 29.7 & 79 & 130 & 50 & 80 & $38.5^{*}$ & 89.6 \\
\hline $\mathrm{D}$ & 41.0 & 95 & 148 & 65 & 83 & 43.9 & 100.0 \\
\hline $\mathrm{E}$ & 49.3 & 106 & 148 & 77 & 71 & 52.0 & 99.3 \\
\hline $\mathbf{F}$ & 60.3 & 120 & 147 & 75 & 72 & 51.0 & 99.3 \\
\hline
\end{tabular}

\#Fish in Group A were transferred to high temperature $\left(18^{\circ} \mathrm{C}\right)$ over 10 days, those in other groups over 2 or 3 days.

'Percentage of females followed by an asterisk deffer significantly from the theoretical 1:1 sex ratio $(P<0.05)$. 


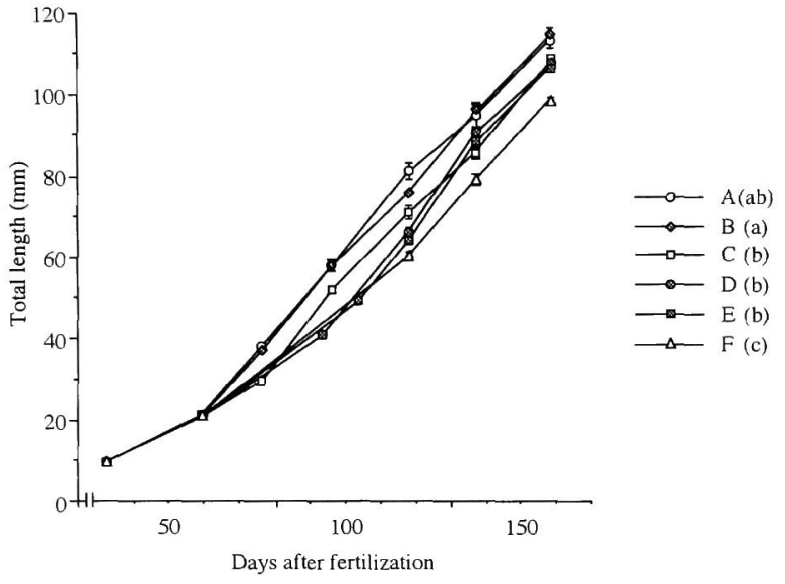

Fig. 2, Growth rate of each temperature treatment group in Verasper moseri.

Values are means \pm SE for 13-43 fish. Significant differences in TL among groups are indicated by different lettering.

the gonads. Clusters of oogonia in mitosis were first observed in ovaries of $56 \mathrm{~mm}$ TL females (Fig. 3A, B). In the other type of gonad, the germ cells remained quiescent and in low numbers until the fish were more than $54 \mathrm{~mm}$ in $\mathrm{TL}$ (Fig. 3C).

\section{Discussion}

The results of the present study demonstrate that the sex inclines towards male if barfin flounder is reared at high temperatures $\left(18^{\circ} \mathrm{C}\right)$. Gradually increasing the temperature of the $10 \mathrm{~mm}$ TL groups to $18^{\circ} \mathrm{C}$ yielded $100 \%$ males while extended exposure to low temperatures produced sex ratios near $1: 1$. The gradual increase in the proportion of females with increase of exposure days at $14^{\circ} \mathrm{C}$ might be explained by the observed differences in individual growth rates of fish and/or genetic sensitivity period to temperature. Thus, genetic females easily reverse their sex to male, while genetic males appear little affected by temperature indicating that the genetic male of the barfin flounder is a very stable sex.

In hirame flounder Paralichthys olivaceus the male of which is heterogametic (XX female-XY male), the sex ratios in gynogenetic diploids and their progeny were previously examined after temperature manipulations. ${ }^{7)}$ When the fish were held under high $\left(25-27.5^{\circ} \mathrm{C}\right)$ or low $\left(15^{\circ} \mathrm{C}\right)$ temperature conditions during larval development, sex reversal of genetic females to phenotypic males was frequently induced. However, intermediate temperatures $\left(20^{\circ} \mathrm{C}\right)$ were hardly effective in inducing sex reversal to phenotypic males. Moreover, reversal from genetic males into phenotypic females could not be demonstrated. In contrast, although the channel catfish Ictalurus puncta$t u s^{13)}$ and the sockeye salmon Oncorhynchus nerk ${ }^{14)}$ have an XX female-XY male sex determination system, genetic males of these species could be feminized by increasing the water temperature. However, there is no report on low temperature effects on the sex ratio in these species. Other fishes, such as some atherinids, e.g., the Atlantic silverside Menidia menidia ${ }^{15)}$ and the pejerry Odontesthes

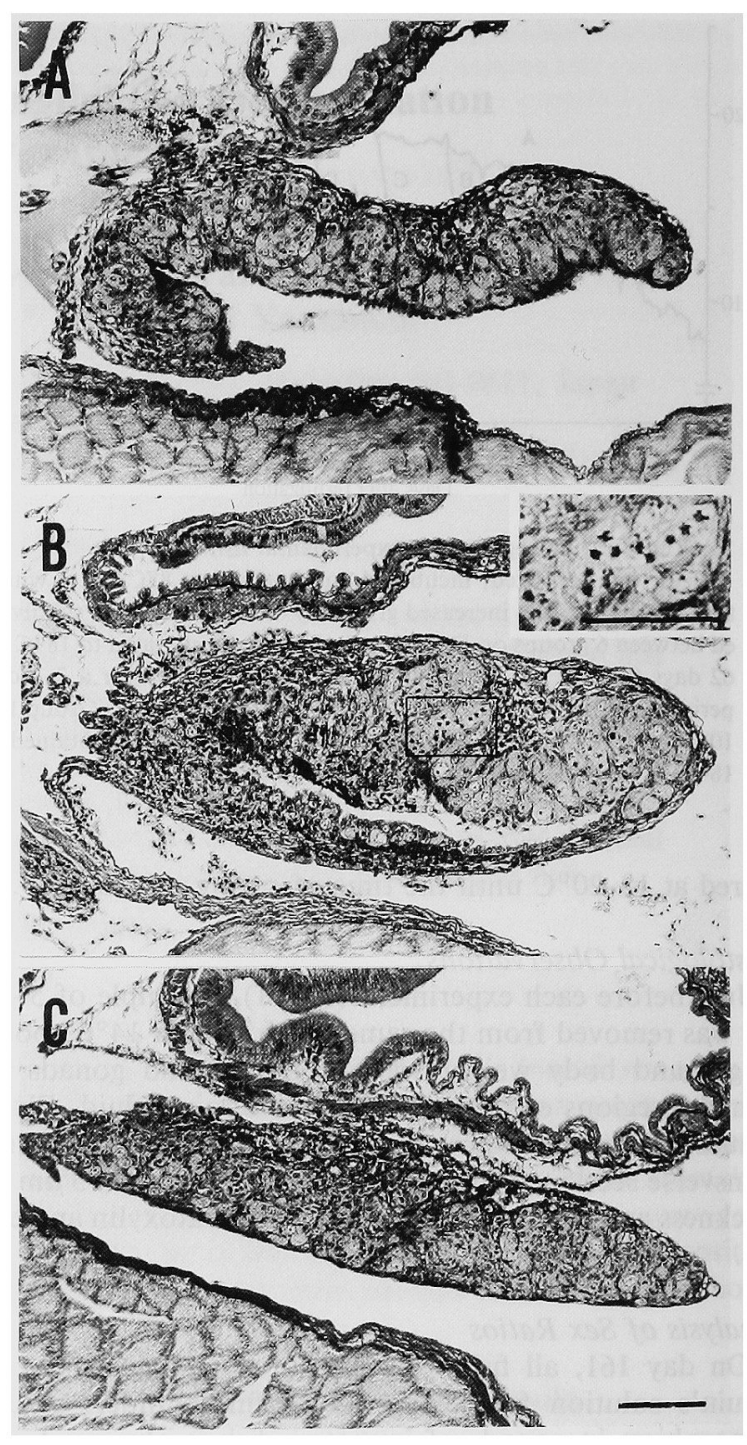

Fig. 3. Gonadal differentiation in Verasper moseri.

Scale $=0.5 \mu \mathrm{m}$. (A) Transverse section of a gonad giving rise to an ovary (total length of $38.0 \mathrm{~mm}$ ). (B) Transverse section of an ovary (total length of $55.7 \mathrm{~mm}$ ). Clusters of oogonia can be seen to undergo mitosis (inset). (C) Transverse section of a testis (total length of $54.3 \mathrm{~mm}$ ).

bonariensis $^{16)}$ are gonochoristic species whose sex inclines to female at low temperatures and to male at high temperatures. These high or low temperature-induced biased sex ratios in many species were initially thought to be generally under genetic control. However, sex determining mechanisms of fish remain little understood. In the case of the barfin flounder, examination of temperature effects on sex ratio using gynogenetic diploids and their progeny is required for a better understanding of the genetic sex determination mechanisms. This will lead to an understanding of the relationship between genetic and phenotypic sexes, allowing the production of the desired ratio of female to male population through temperature control.

The gonadal sex of fish reared at $14^{\circ} \mathrm{C}$ could be recognized as one of two types in fish of TL of $35 \mathrm{~mm}$ and upwards. One type started formation of a presumptive ovari- 
an cavity from the dorsal and ventral edge of the gonad which expanded laterally. The other type of gonad, which was a presumptive testis, was not clearly differentiated until $54.3 \mathrm{~mm}$ TL. Our analyses indicated that sex differentiation takes place at a younger stage in female than in male, corroborating earlier findings obtained from another flounder species. ${ }^{17,18)}$ Sex ratios among temperature treatment groups showed that fish below $30-40 \mathrm{~mm}$ in TL were most sensitive to temperature manipulation. The onset of the temperature-sensitive period was not assessed in this study, but fish in Group A, which were exposed to gradually increasing water temperature when $10.1 \mathrm{~mm}$ in TL (32 days after fertilization), yielded $100 \%$ male, while those in Group B, subjected to increasing temperatures at a TL of $20.6 \mathrm{~mm}$ (61 days after fertilization), produced $16.5 \% \mathrm{fe}-$ male. This implies that the starting point of the temperature-insensitive period falls between 10.1 and $20.6 \mathrm{~mm}$ TL. The end of the temperature-sensitive period agrees well with the starting time of gonadal sex differentiation which was first evidenced at TL of $35 \mathrm{~mm}$ by histological techniques. Indeed, phenotypic sex is first determined by both temperature and some genetic factors before gonadal differentiation is recognizable morphologically. This information suggests that temperature influences the outcome of primary sex differentiation rather than causing a secondary reversal of gonadal sex. Similar findings have been reported for other fish having temperature-dependent sex determination. ${ }^{2)}$

Growth is one of the most important factors for cultivated fish. High temperatures $\left(18^{\circ} \mathrm{C}\right)$ promote the speed with which metabolic processes occur. In this study, too, higher growth rates were recorded for the groups switched to $18^{\circ} \mathrm{C}$ compared to those kept at $14^{\circ} \mathrm{C}$. When all groups were reared simultaneously at $18^{\circ} \mathrm{C}$, the mean total length of Groups B, C, D and E caught up with that of Group A. Sex ratios of Groups $E$ and $F$ were $1: 1$, despite the lower growth rates in Group $F$ compared to Group $E$. The results of growth rates and sex ratio indicate that the best rearing condition for aquaculture is to maintain the fry at $14^{\circ} \mathrm{C}$ until reaching at least $49.3 \mathrm{~mm}$ TL (106 days after fertilization).

In this paper, we have described an effect of high temperatures on sex determination in barfin flounder. These effects are induced especially if fry are subjected to increased temperature regimes before reaching $20 \mathrm{~mm}$ in TL. Low temperature effects, as well as the genetic sex determination system, remain unclear. Moreover there is a general lack of information on sex determining effects of $\mathrm{pH}$. Since several environmental factors may play a role, as has been seen for instance in Apistogramma spp., ${ }^{6)}$ a multi-factorial control system could be at work in the barfin flounder. It is obvious that, in order to set up suitable culture conditions in this species, many questions pertaining to genetic sex determinants and the role of other environmental factors need to be addressed in future reseach.

Acknowledgments We thank Dr. Mark Lokman, University of Otago,
New Zealand, for his critical reading of the manuscript. This study was supported in part by a Grant for Scientific Research from the Fisheries Agency, Japan and Hokkaido, and by a Research Fellowship of the Japan Society for the Promotion of Science for Young Scientists.

\section{References}

1) Y. Ojima: Fish Cytogenetics, Suikosha Press, Tokyo, Japan, 1989, pp. 50-64 (in Japanese).

2) D. O. Conover and S. W. Heins: The environmental and genetic components of sex ratio in Menidia menidia (Pisces: Atherinidae). Copeia, 3, 732-743 (1987).

3) J. F. Baroiller, D. Chourrout, A. Fostier, and B. Jalabert: Temperature and sex chromosomes govern sex ratios of the mouthbrooding cichlid fish Oreochromis niloticus. J. Exp. Zool., 273, 216-223 (1995).

4) C. A. Strüsmann, S. Moriyama, E. F. Hanke, J. C. Calsina Cota, and $\mathrm{F}$. Takashima: Evidence of thermolabile sex determination in pejerrey. J. Fish Biol., 48, 643-651 (1996).

5) D. A. Rubin: Effect of $\mathrm{pH}$ on sex ratio in cichlids and a poeciliid (Teleostei). Copeia, 1, 233-235 (1985).

6) U. Rümer and W. Beisenherz: Environmental determination of sex in Apistogramma (Cichlidae) and two other freshwater fishes (Teleostei). J. Fish Biol., 48, 714-725 (1996).

7) E. Yamamoto: Studies on sex-manipulation and production of cloned populations in hirame flounder, Paralichthys olivaceus (Temminck et Schlegel). Bull. Tottori Pref. Fish. Exp. Stn., 34, 1-145 (1995) (in Japanese).

8) R. Johnstone, T. H. Simpson, and A. F. Youngson: Sex reversal in salmonid culture. Aquaculture, 13, 115-134 (1978).

9) R. Johnstone, T. H. Simpson, and A. F. Walker: Sex reversal in salmonid culture Part III. The production of all female populations of brook trout. Aquaculture, 18, 241-252 (1979).

10) F. W. Goetz, E. M. Donaldson, G. A. Hunter, and H. M. Dye: Effect of estradiol-17 $\beta$ and $17 \alpha$-methyltestosterone on gonadal differentiation in the coho salmon, Oncorhynchus kisutch. Aquaculture, 17, 267-278 (1979).

11) T. Mori, K. Kawamata, S. Mizuno, S. Adachi, and K. Yamauchi: The feminization of the barfin flounder, Verasper moseri by oral administration of estradiol-17 B. Sci. Rep. Hokkaido. Fish. Exp. Sta., 46, 1-6 (1995).

12) T. Matsubara, K. Watanabe, T. Yamaname, and T. Kayaba: Application of ultrasonography to non-invasive sexing based on the sexual dimorphism in gonads of immature barfin flounder Verasper moseri. Fisheries Sci., 65, 244-247 (1999).

13) R. Patiño, K. B. Davis, J. E. Schoore, C. Uguz, C. A. Strüsmann, N. C. Parker, B. A. Simco, and C. A. Goudie: Sex differentiation of channel catfish gonads: Normal development and effects of temperature. J. Exp. Zool., 276, 209-218 (1996)

14) J. K. Craig, C. J. Foote, and C. C. Wood: Evidence for temperature-dependent sex determination in sockeye salmon (Oncorhynchus nerka). Can. J. Fish. Aquat. Sci., 53, 141-147 (1996).

15) D. O. Conover and M. H. Fleisher: Temperature-sensitive period of sex determination in the Atlantic silverside, Menidia menidia. Can. J. Fish. Aquat. Sci., 43, 514-520 (1986).

16) C. A. Strüssmann, J. C. Calsina Cota, G. Phonlor, H. Higuchi, and F. Takashima: Temperature effects on sex differentiation of two South American atherinids, Odontesthes argentinensis and Patagonina hatcheri. Env. Biol. Fish, 47, 143-154 (1996).

17) N. Suzuki, M. Tamura, I. Ohuthi, K. Hiromatsu, and T. Sugihara: Gonadal sex differentiation of hatchery-reared flounder, Limanda yokohamae. Suisanzoshoku, 40, 189-199 (1992) (in Japanese).

18) H. Tanaka: Gonadal sex differentiation in founder, Paralichthys olivaceus. Bull. Natl. Res. Inst. Aquaculture, 11, 7-19 (1987) (in Japanese) 